\title{
Effects of Fire Compartmentation and Smoke Exhaust Measures on Smoke Spread Caused by Cable Fire in Utility Tunnel
}

\author{
Li Xin, ${ }^{1}$ Zhang Yuanyuan, ${ }^{1}$ Jia Boyan, ${ }^{2}$ Zhang Guowei $\mathbb{D}^{1,3}$ and Zheng $\mathrm{Li}^{1}$ \\ ${ }^{1}$ School of Safety Engineering, China University of Mining and Technology, Xuzhou,221116, China \\ ${ }^{2}$ State Grid Hebei Electric Power Co., Ltd, Electric Power Research Institute, Hebei 050022, China \\ ${ }^{3}$ Jiangsu Key Laboratory of Fire Safety in Urban Underground Space, China University of Mining and Technology, \\ Xuzhou 221116, China \\ Correspondence should be addressed to Zhang Guowei; zgw119xz@126.com
}

Received 23 June 2021; Accepted 2 November 2021; Published 19 November 2021

Academic Editor: Adolfo Preciado

Copyright (c) $2021 \mathrm{Li}$ Xin et al. This is an open access article distributed under the Creative Commons Attribution License, which permits unrestricted use, distribution, and reproduction in any medium, provided the original work is properly cited.

\begin{abstract}
Investigating the behavior of fire smoke in utility tunnel as well as smoke prevention and control measures are of vital significance for exhausting smoke from utility tunnel, realizing efficient firefighting and rescue, and guaranteeing the normal operation of cities. Taking utility tunnel as the research background, this paper builds a simulation calculation model for fire smoke prevention and control in the utility tunnel using PyroSim numerical simulation software and explores the rules of smoke spread under conditions such as building ceiling screen, changing fire compartmentation tightness, and adding smoke exhaust facilities. According to study results, before the tunnel was filled with smoke, ceiling screens lowered smoke spread rate, and smoke spread rate was inversely proportional to the ceiling screen height. When the fire door was opened, fire smoke spread to the adjacent fire compartment, and smoke spread rate was directly proportional to the fire door opening angle. Before the tunnel was filled up, mechanical smoke exhaust facilities significantly lowered the smoke spread rate by as much as $50 \%$. When the entire tunnel was full of smoke, mechanical smoke exhaust facilities significantly reduced the smoke concentration in the utility tunnel; smoke layer temperature dropped by as much as $32^{\circ} \mathrm{C}$, while visibility improved by as much as $66 \%$. By studying smoke spread in utility tunnel, this paper aims to determine the optimal measures of preventing and controlling smoke spread in utility tunnel. This paper could also offer some reference for practical engineering applications in smoke prevention and control in utility tunnel.
\end{abstract}

\section{Introduction}

As a comprehensive pipe gallery, utility tunnel is not only an urban underground tunnel space accommodating various kinds of engineering pipelines (such as power, communication, fuel, heating, and water supply and drainage pipelines) but also important infrastructure and "lifeline" supporting the normal operation of cities [1]. To promote utility tunnel construction, the Chinese government has introduced a series of documents since 2013, such as the Opinions of the State Council on Strengthening Urban Infrastructure Construction and the Guiding Opinions of the General Office of the State Council on Strengthening the Administration of Urban Underground Pipelines [2].
With the acceleration of urban modernization in China, utility tunnels are seeing constant increases in both pipeline type and pipeline density, accompanied by more and more fire accidents $[3,4]$. Since utility tunnels accommodate all kinds of cables essential for the normal operation of a city, in case of a fire, the vast amount of smoke produced by cable combustion will soon fill up the utility tunnel, posing significant difficulties to fire rescue operation and jeopardizing the normal operation of the city [5-7]. Thus, investigating the behavior of fire smoke in utility tunnels as well as smoke prevention and control measure is highly important for exhausting smoke from utility tunnel, realizing efficient firefighting and rescue operations and guaranteeing the normal operation of cities [8-10]. 
Scholars at home and abroad have preliminarily explored how to prevent and control fire in utility tunnels. Fu et al. built a reduced-scale experimental model for underground tunnels based on theoretical analysis and used it to study the rules of the flow field and concentration field of cable fire smoke in the underground utility tunnel [11]. Liu et al. put forward a reduced-scale model for the Foziling Tunnel in Nanning based on similarity theory, plotted it using SketchUp software, and used it to investigate the effect of wind speed on the rules of smoke flow in utility tunnel. In order to explore the transport characteristics of fire smoke in tunnels under different smoke exhaust conditions [12], Jiang proposed a theoretical model for increasing CO concentration with time in the tunnel, validated the model, and revealed the differences between $\mathrm{CO}$ concentration and temperature in the longitudinal distribution in the tunnel [13]. Turkish scholar Merve Altay et al. claimed that sound ventilation conditions would contribute to the prevention and control of fire smoke, explored the effects of vehicles and other obstacles on ventilation in highway tunnels, and found that these obstacles greatly affected smoke flow pattern and critical ventilation speed and were likely to cause smoke backflow [14].

This paper first builds a numerical simulation model using field simulation software and then simulates smoke spread in a utility tunnel under conditions such as building ceiling screen, changing fire compartmentation tightness, and adding smoke exhaust facilities. On this basis, this paper analyzes and summarizes simulation results as well as proposes some specific smoke prevention and control measures.

\section{Simulation Model for Fire in Utility Tunnel}

\subsection{Modeling}

2.1.1. Model Generalization. In the modeling process, we referred to a standard segment of utility tunnel in a city [15]. This segment was $4 \mathrm{~km}$ in total length. The utility tunnel was composed of a power cable cabin, a water pipeline and communication cable cabin, a steam pipeline cabin, and a fuel pipeline cabin (Figure 1) (unit: $\mathrm{mm}$ ).

In this study, the focus was placed on the smoke produced by a fire in the power cable cabin of the utility tunnel. The utility tunnel model was $210.0 \mathrm{~m} \times 3.5 \mathrm{~m} \times 4.0 \mathrm{~m}$ in size. In the utility tunnel, a fire compartment was $200 \mathrm{~m}$ in length. A fire partition was erected at the $200 \mathrm{~m}$ site of the model and designed with a grade A fire door (normally closed) [16].

2.1.2. Building of the Smoke Exhaust System. The smoke exhaust capacity of the smoke exhaust system of the utility tunnel was calculated 6 times/hour $[17,18]$.

2.1.3. Cable Arrangement Mode. The tunnel was distributed with $10 \mathrm{kV}$ and $110 \mathrm{kV}$ high-voltage cables on each side. In model simulation, these cables were idealized as long and narrow objects $204 \mathrm{~m} \times 0.7 \mathrm{~m} \times 0.15 \mathrm{~m}$ in size (see cable arrangement mode in Table 1).
The cables on the market have different ignition points due to different insulating materials. The ignition point of ordinary PVC materials is about $260^{\circ} \mathrm{C}$, the pyrolysis temperature of rubber-like substances is $200-500^{\circ} \mathrm{C}$, and the ignition point of cross-linked vinyl chloride materials is about $380^{\circ} \mathrm{C}$. The materials used in this simulation are mainly nanoscale $\mathrm{Sb}_{2} \mathrm{O}_{3} / \mathrm{PVC}$ materials, and the ignition point is set to $300^{\circ} \mathrm{C}$. This material forms a Sb-CI flame retardant system through the addition of $\mathrm{Sb}_{2} \mathrm{O}_{3}$. The halogen in the PVC material to block the chain reaction during the combustion process and achieve the purpose of flame retardancy [12].

In the model $(X=99 \mathrm{~m})$, a fire source with an area of $0.5 \mathrm{~m}^{2}$ was prepared close to the lower boundary of the tunnel. The increase of the fire source's heat release rate was directly proportional to $t^{2}$. As medium-speed fire, the fire source had a maximum heat release rate of $750 \mathrm{~kW}$ [13].

2.1.4. Ceiling Screen Layout. The utility tunnel was a fully enclosed structure, and the fire source was located at the $99.0 \mathrm{~m}$ site on its longest side. To save cost, two ceiling screens of the same size were erected at $70.0 \mathrm{~m}$ and $140.0 \mathrm{~m}$ ceiling positions in the simulation.

2.2. Fire Scenario Settings. Fire scenarios were determined according to the goal of this study. Table 2 shows the specific fire scenarios set for the fire simulation in the utility tunnel:

2.3. Mesh Building. According to the user manual, the size of the mesh affects the accuracy of the simulation results. Therefore, the size of the grid cannot be selected arbitrarily during the simulation and needs to be confirmed by calculation. The calculation formula is as follows:

$$
\begin{aligned}
& D^{*}=\left(\frac{Q^{*}}{\beta_{\infty} c_{p} T_{\infty} \sqrt{g}}\right)^{2 / 5}, \\
& \frac{D^{*}}{\delta x} \approx 4 \sim 10,
\end{aligned}
$$

where $D^{*}$ is the diameter of the fire source; $Q^{*}$ is the rate of heat release; $\beta_{\infty}$ is the density of the air under the initial conditions; $c_{p}$ is the constant pressure ratio of the air under the initial conditions; $T_{\infty}$ is the initial temperature of the environment; $g$ is the acceleration of gravity under the initial conditions; and $\delta x$ is the mesh size.

The maximum heat release rate of the fire source is 1.5 MW. At this time, $Q^{*}=1500 \mathrm{~kW}, D^{*}=10, \delta x$ $=0.11 \mathrm{~m}$. Taking into account the time-consumption and computer performance of the simulation, the mesh size is set to $0.15 \mathrm{~m} \times 0.15 \mathrm{~m} \times 0.15 \mathrm{~m}$ in the actual simulation. Along the IJK direction of the space coordinate system, the number of grids adopts Poisson's ratio distribution. In this simulation, a total of $1,227,744$ meshes were divided. 


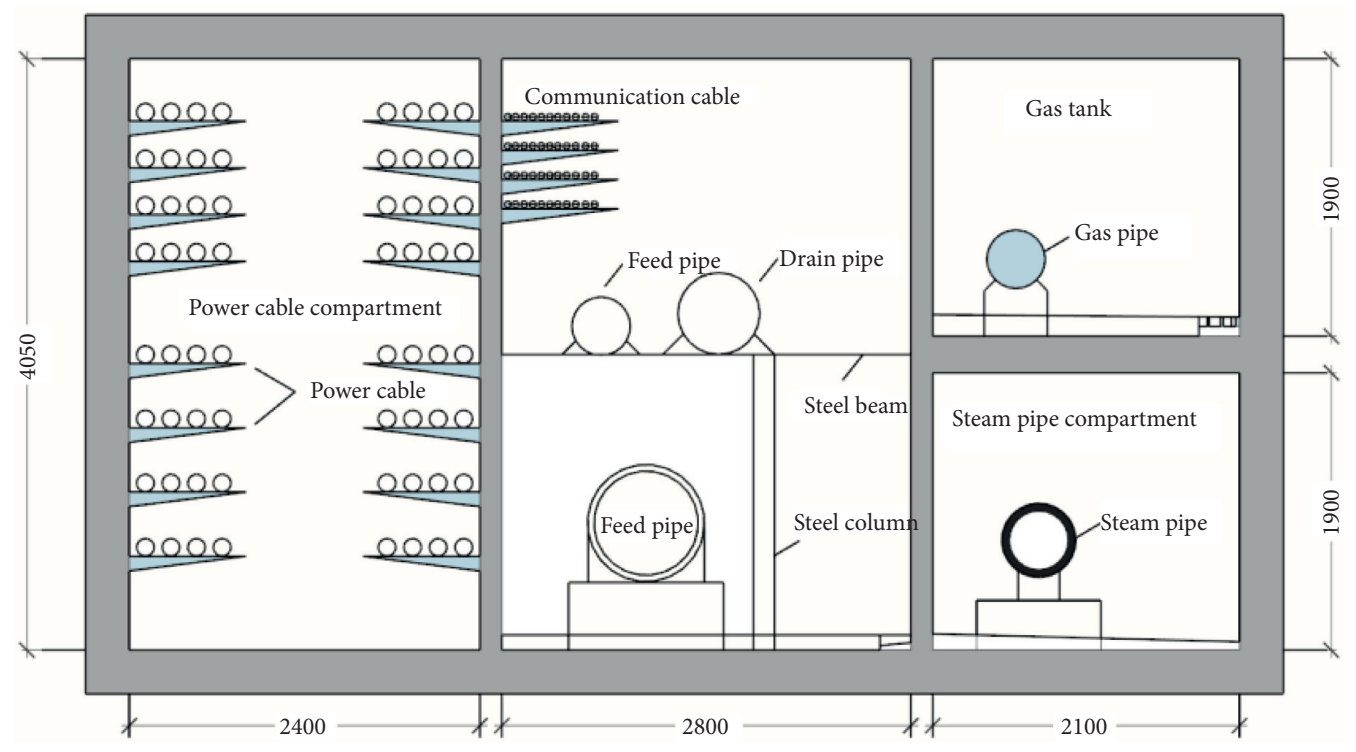

Figure 1: Standard segment section of utility tunnel.

TABLe 1: Cable arrangement mode.

\begin{tabular}{lcc}
\hline Cable type $(\mathrm{kV})$ & Interlayer spacing $(\mathrm{m})$ & Bottom layer height $(\mathrm{m})$ \\
\hline 10 & 0.8 & 0.6 \\
110 & 0.85 & 0.6 \\
\hline
\end{tabular}

\section{Fire Dynamics Simulator (FDS) Simulation Results and Analysis}

\subsection{Smoke Spread}

3.1.1. Effect of Ceiling Screen on Smoke Spread. Ceiling screens $0.5 \mathrm{~m}$ and $1 \mathrm{~m}$ in height were erected at the ceiling positions of the tunnel under working conditions 2 and 3 . Analysis showed that, in the early stage of fire development, the smoke took a longer time to spread to both ends of the tunnel and fill up the entire tunnel under working conditions 2 and 3 compared to working condition 1 . The time taken was directly proportional to the ceiling screen height.

Ceiling screens lowered the smoke spread rate, and smoke spread rate was inversely proportional to ceiling screen height. The ceiling screen $0.5 \mathrm{~m}$ in size lowered the smoke spread rate by about $12 \%$; the ceiling screen $1.0 \mathrm{~m}$ in size lowered it by about $23 \%$ (see specific comparisons in Table 3 ).

In addition, ceiling screens lowered the smoke spread rate, and the smoke spread rate was inversely proportional to ceiling screen height. Meanwhile, due to the erection of ceiling screens, the smoke concentrations and smoke layer thicknesses in the middle of the tunnel under working conditions 2 and 3 were both greater than those under working condition 1; the smoke layer temperatures under working conditions 2 and 3 were higher than those under working condition 1. At this position, the smoke layer temperature was directly proportional to the ceiling screen height. Relative to the $0.5 \mathrm{~m}$ ceiling screen, the $1.0 \mathrm{~m}$ ceiling screen 1 increased the smoke layer temperature by as much as $21{ }^{\circ} \mathrm{C}$ (see details in Table 4 ).
3.1.2. Effect of Fireproof Sealing on Smoke Spread. As can be known from the simulation results under working conditions 1,4 , and 5, when the fire door was open, the smoke spread rate was barely affected before reaching the two ends of the fire door. However, when smoke reached both ends of the fire door, the smoke layer entered the adjacent fire compartment through the opened fire door. The smoke layer thickness of the utility tunnel segment affected by the fire accident began to grow at a reduced pace. Table 5 offers a comparison of smoke layer thicknesses. Under working conditions 4 and 5, the time taken for the smoke layer to reach tunnel floor was directly proportional to the fire door opening angle. The time taken for the smoke in the adjacent fire compartment to reach the tunnel floor was inversely proportional to the opening angle.

In the open state of the fire door, the air in the adjacent fire compartment entered the utility tunnel segment affected by the fire accident. As a result, cable combustion became more intense in the early stage of fire development, resulting in an increase in smoke layer temperature. Compared to working condition 1, working conditions 4 and 5 had higher smoke layer temperatures. The rise of smoke layer temperature was directly proportional to the fire door opening angle. To be specific, the smoke layer temperature under an opening angle of $90^{\circ}$ was $60^{\circ} \mathrm{C}$ higher than that under $45^{\circ}$ at most and $68{ }^{\circ} \mathrm{C}$ higher than that under closed state (see specific comparisons in Table 6).

3.1.3. Effect of Smoke Exhaust Facilities on Smoke Spread. On the basis of working condition 1, working condition 6 introduced smoke exhaust facilities to the tunnel ceiling. As can be found through a comparison of simulation results, because of the hot smoke exhaust passing through the exhaust port of the utility tunnel, the smoke spread rate, smoke layer thickness, and smoke layer concentration in the tunnel significantly declined. As detailed in Table 7, the smoke 
TABLE 2: Fire scenario settings.

\begin{tabular}{lccc}
\hline Working condition & Ceiling screen height $(\mathrm{m})$ & Opening angle of the fire door & Number of smoke exhaust fans \\
\hline Working condition 1 & 0.0 & $0^{\circ}$ & 0 \\
Working condition 2 & 0.5 & $0^{\circ}$ & 0 \\
Working condition 3 & 1.0 & $0^{\circ}$ & 0 \\
Working condition 4 & 0.0 & $90^{\circ}$ & 0 \\
Working condition 5 & 0.0 & $45^{\circ}$ & 0 \\
Working condition 6 & 0.0 & $0^{\circ}$ & 4 \\
\hline
\end{tabular}

TABLE 3: Comparison of smoke spread under working conditions 1, 2, and 3.

\begin{tabular}{|c|c|c|}
\hline Working condition & Screenshot of smoke spread & Description \\
\hline \multirow{2}{*}{ Working condition 1} & 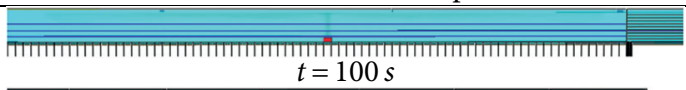 & Horizontal spread distance $68 \mathrm{~m}$ \\
\hline & 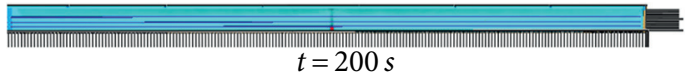 & Horizontal spread distance $195 \mathrm{~m}$ \\
\hline \multirow{3}{*}{ Working condition 2} & $\bar{~}$ & Horizontal spread distance $68 \mathrm{~m}$ \\
\hline & & Horizontal spread distance $180 \mathrm{~m}$ \\
\hline & $t=200 \mathrm{~s}$ & \\
\hline \multirow{4}{*}{ Working condition 3} & 1 & Horizontal spread distance $67 \mathrm{~m}$ \\
\hline & $t=100 \mathrm{~s}$ & \\
\hline & 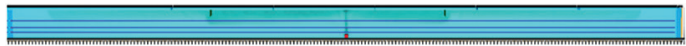 & Horizontal spread distance $165 \mathrm{~m}$ \\
\hline & $t=200 \mathrm{~s}$ & \\
\hline
\end{tabular}

TABLE 4: Comparison of smoke layer temperatures under working conditions 1, 2, and 3.

\begin{tabular}{|c|c|c|}
\hline Working condition & Screenshot of smoke layer temperature & Description \\
\hline \multirow{4}{*}{ Working condition 1} & 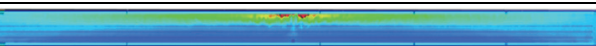 & Smoke layer temperature $343^{\circ} \mathrm{C}$ \\
\hline & $t=500 \mathrm{~s}$ & \multirow{3}{*}{ Smoke layer temperature $382^{\circ} \mathrm{C}$} \\
\hline & $=$ & \\
\hline & $t=700 \mathrm{~s}$ & \\
\hline \multirow{4}{*}{ Working condition 2} & 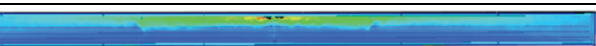 & Smoke layer temperature $359^{\circ} \mathrm{C}$ \\
\hline & $t=500 \mathrm{~s}$ & \multirow{3}{*}{ Smoke layer temperature $400^{\circ} \mathrm{C}$} \\
\hline & $\sqrt{-1-10}$ & \\
\hline & $t=700 \mathrm{~s}$ & \\
\hline \multirow{4}{*}{ Working condition 3} & $\sqrt{2+2}$ & Smoke layer temperature $380^{\circ} \mathrm{C}$ \\
\hline & $t=500 \mathrm{~s}$ & \multirow{3}{*}{ Smoke layer temperature $415^{\circ} \mathrm{C}$} \\
\hline & 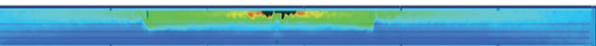 & \\
\hline & $t=700 \mathrm{~s}$ & \\
\hline
\end{tabular}

TABle 5: Comparison of smoke layer thickness under working conditions 1, 4, and 5.

\begin{tabular}{lcccccc}
\hline Time & $100 \mathrm{~s}(\mathrm{~m})$ & $200 \mathrm{~s}(\mathrm{~m})$ & $300 \mathrm{~s}(\mathrm{~m})$ & $400 \mathrm{~s}(\mathrm{~m})$ & $500 \mathrm{~s}(\mathrm{~m})$ & $700 \mathrm{~s}(\mathrm{~m})$ \\
\hline Working condition 1 & 0.6 & 0.8 & 1.6 & 3.2 & 3.75 & 3.75 \\
Working condition 4 & 0.6 & 0.8 & 1.5 & 2.8 & 3.35 & 3.75 \\
Working condition 5 & 0.6 & 0.8 & 1.5 & 3.0 & 3.55 \\
\hline
\end{tabular}

TABLE 6: Comparison of smoke layer temperatures under working conditions 1, 4, and 5.

\begin{tabular}{|c|c|c|c|c|c|c|}
\hline Time & $100 \mathrm{~s}\left({ }^{\circ} \mathrm{C}\right)$ & $200 \mathrm{~s}\left({ }^{\circ} \mathrm{C}\right)$ & $300 \mathrm{~s}\left({ }^{\circ} \mathrm{C}\right)$ & $400 \mathrm{~s}\left({ }^{\circ} \mathrm{C}\right)$ & $500 \mathrm{~s}\left({ }^{\circ} \mathrm{C}\right)$ & $700 \mathrm{~s}\left({ }^{\circ} \mathrm{C}\right)$ \\
\hline Working condition 1 & 110 & 140 & 270 & 300 & 343 & 382 \\
\hline Working condition 4 & 110 & 160 & 295 & 340 & 390 & 450 \\
\hline Working condition 5 & 110 & 150 & 290 & 330 & 380 & 390 \\
\hline
\end{tabular}

TABLE 7: Comparison of smoke spread under working conditions 1 and 6.

\begin{tabular}{|c|c|c|c|c|c|c|c|}
\hline \multicolumn{2}{|l|}{ Time } & $100 \mathrm{~s}(\mathrm{~m})$ & $200 \mathrm{~s}(\mathrm{~m})$ & $300 \mathrm{~s}(\mathrm{~m})$ & $400 \mathrm{~s}(\mathrm{~m})$ & $500 \mathrm{~s}(\mathrm{~m})$ & $700 \mathrm{~s}(\mathrm{~m})$ \\
\hline \multirow{2}{*}{ Horizontal spread distance } & Working condition 1 & 66 & 165 & 200 & 200 & 200 & 200 \\
\hline & Working condition 6 & 60 & 110 & 200 & 200 & 200 & 200 \\
\hline \multirow{2}{*}{ Smoke layer thickness } & Working condition 1 & 0.60 & 0.80 & 1.60 & 3.20 & 3.75 & 3.75 \\
\hline & Working condition 6 & 0.54 & 0.60 & 1.20 & 2.40 & 3.50 & 3.75 \\
\hline
\end{tabular}


TABLE 8: Comparison of smoke layer temperatures under working conditions 1 and 6.

\begin{tabular}{lcccccc}
\hline Time & $100 \mathrm{~s}\left({ }^{\circ} \mathrm{C}\right)$ & $200 \mathrm{~s}\left({ }^{\circ} \mathrm{C}\right)$ & $300 \mathrm{~s}\left({ }^{\circ} \mathrm{C}\right)$ & $400 \mathrm{~s}\left({ }^{\circ} \mathrm{C}\right)$ & $500 \mathrm{~s}\left({ }^{\circ} \mathrm{C}\right)$ & $700 \mathrm{~s}\left({ }^{\circ} \mathrm{C}\right)$ \\
\hline Working condition 1 & 110 & 140 & 270 & 300 & 343 & 382 \\
Working condition 6 & 90 & 130 & 260 & 290 & 320 & 350 \\
\hline
\end{tabular}

TABLE 9: Comparison of visibility changes under working conditions 1, 2, and 3.

\begin{tabular}{lll}
\hline Working condition & \multicolumn{1}{c}{ Screenshot of visibility changes } & Vescription \\
Working condition 1 & Visibility at the middle of the tunnel $16.3 \mathrm{~m}$ \\
Working condition 2 & $t=400 \mathrm{~s}$ & Visibility at the middle of the tunnel $11.4 \mathrm{~m}$ \\
\hline & $t=400 \mathrm{~s}$ & Visibility at the middle of the tunnel $6.4 \mathrm{~m}$ \\
Working condition 3 & $t=500 \mathrm{~s}$ & Visibility at the middle of the tunnel $6 \mathrm{~m}$
\end{tabular}

TABLE 10: Comparison of visibility changes under working conditions 1, 4, and 5 .

\begin{tabular}{lccc}
\hline Time & $400 \mathrm{~s}(\mathrm{~m})$ & $500 \mathrm{~s}(\mathrm{~m})$ & $700 \mathrm{~s}(\mathrm{~m})$ \\
\hline Working condition 1 & 16.3 & 7.0 & 3.0 \\
Working condition 4 & 17.0 & 8.5 & 4.4 \\
Working condition 5 & 16.5 & 7.5 & 3.8 \\
\hline
\end{tabular}

TABLE 11: Comparison of visibility changes under working conditions 1 and 6.

\begin{tabular}{lccc}
\hline Time & $400 \mathrm{~s}(\mathrm{~m})$ & $500 \mathrm{~s}(\mathrm{~m})$ & $700 \mathrm{~s}(\mathrm{~m})$ \\
\hline Working condition 1 & 16.3 & 7.0 & 3.0 \\
Working condition 6 & 19.8 & 10.0 & 5.0 \\
\hline
\end{tabular}

spread rate declined by as much as $50 \%$, and smoke layer thickness declined by as much as $25 \%$.

Due to the exhausting of hot smoke out of the utility tunnel, the smoke layer temperature under working condition 6 was significantly lower than that under working condition 1 within the same period, with a maximum drop of 32 (Table 8 ).

\subsection{Analysis on Visibility Changes}

3.2.1. Effect of Ceiling Screen on Visibility. As can be known from the changes of the visibility slice under working conditions 2,3 , and 1 , before the tunnel was completely filled up by smoke, ceiling screens increased smoke layer thickness and concentration in the smoke cabin, thus reducing the visibility at the middle of the tunnel. The degree of visibility reduction was directly proportional to the ceiling screen height. At $400 \mathrm{~s}-500 \mathrm{~s}$, ceiling screens exerted a significant effect on visibility, which declined by as much as $46 \%$ (Table 9).

3.2.2. Effect of Fireproof Sealing on Visibility. According to the simulation results under working conditions 1,4 , and 5 , when the fire door was opened, the visibility of the utility tunnel segment affected by the fire accident increased at the visibility slice position. The increasing amplitude of visibility was directly proportional to the fire door opening angle, as shown in Table 10 .

3.2.3. Effect of Smoke Exhaust Facilities on Visibility. Through analyzing the simulation results under working conditions 6 and 1 , it can be seen that, when smoke exhaust fans were deployed, the visibility in the utility tunnel increased significantly by as much as about $66 \%$ (Table 11 ).

3.3. Changes of Smoke Components and Concentration. In case of a fire in utility tunnel, smoke components are relatively complicated. In this study, only carbon monoxide and carbon dioxide were selected for concentration analysis.

A comparison of the simulation results under working conditions 1, 2, and 3 revealed that, when ceiling screens were erected, carbon monoxide and carbon dioxide increased at a faster pace, but their maximum concentration values remained unchanged. The increased rates of carbon monoxide and carbon dioxide gases were directly proportional to ceiling screen height.

In the same vein, the simulation results under working conditions 1, 4, and 5 showed that when the fire door was opened, carbon monoxide and carbon dioxide increased at a 


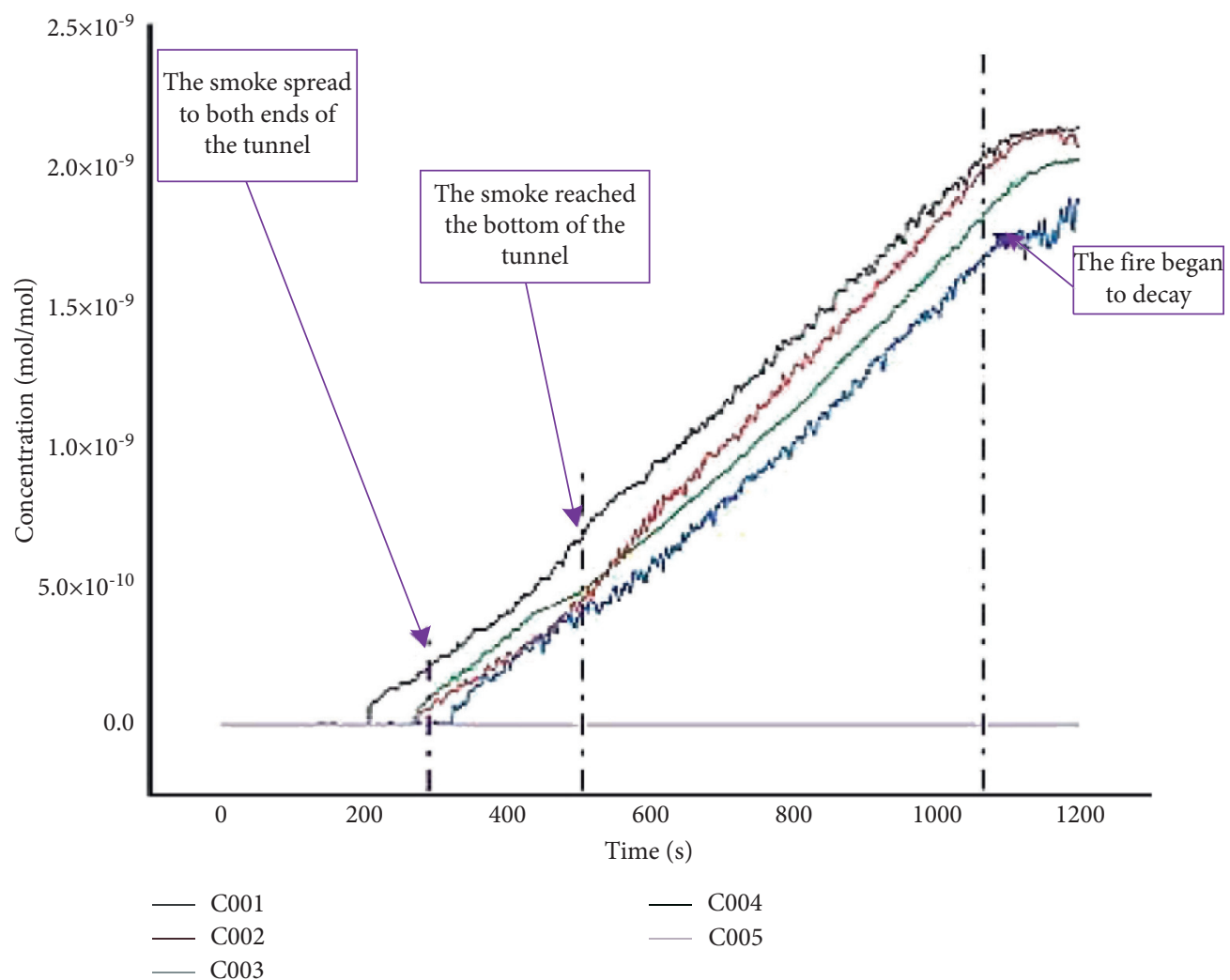

(a)

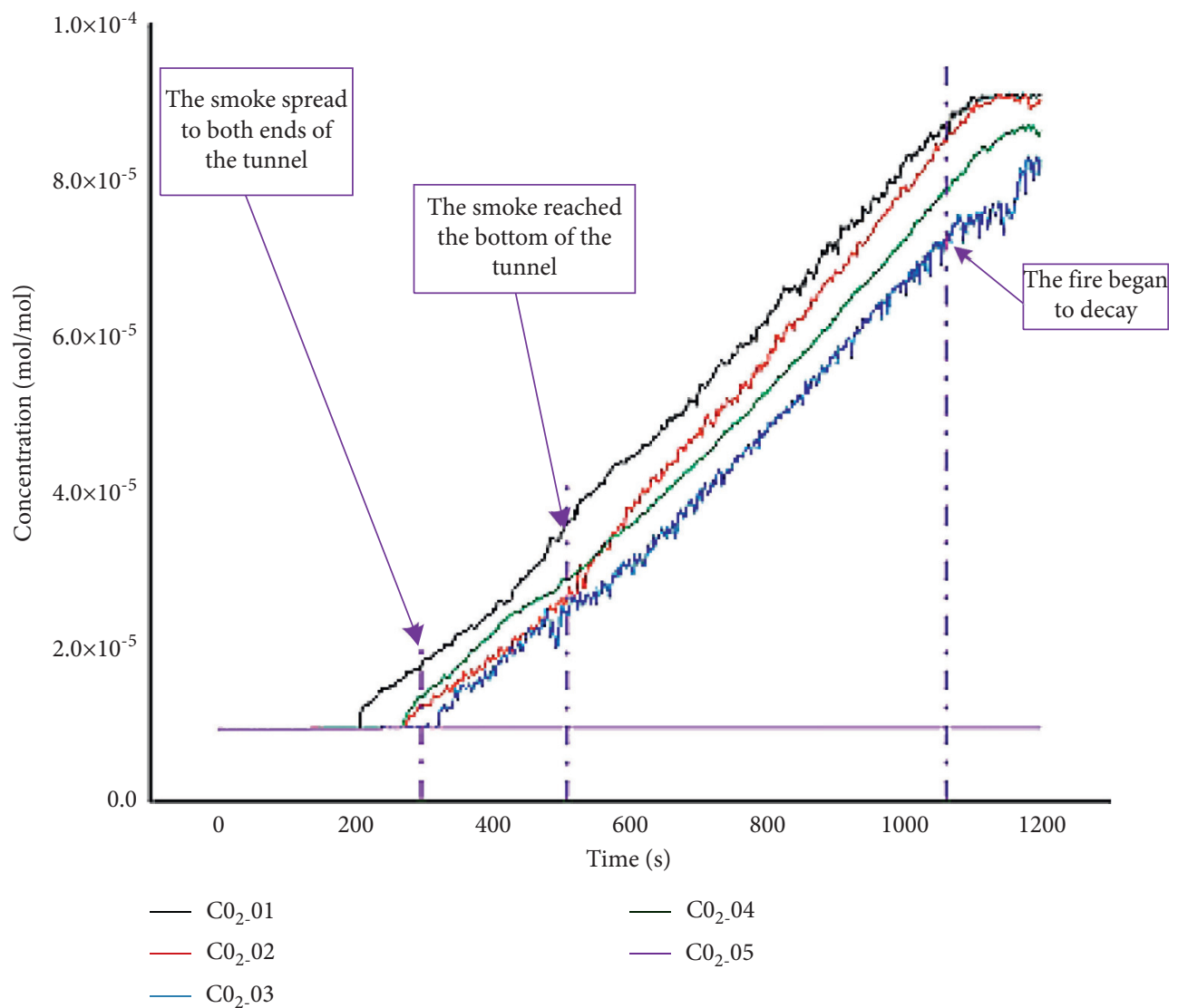

(b)

Figure 2: Comparison of smoke concentration changes under working condition 1. (a) Carbon monoxide concentration. (b) Carbon dioxide concentration. 


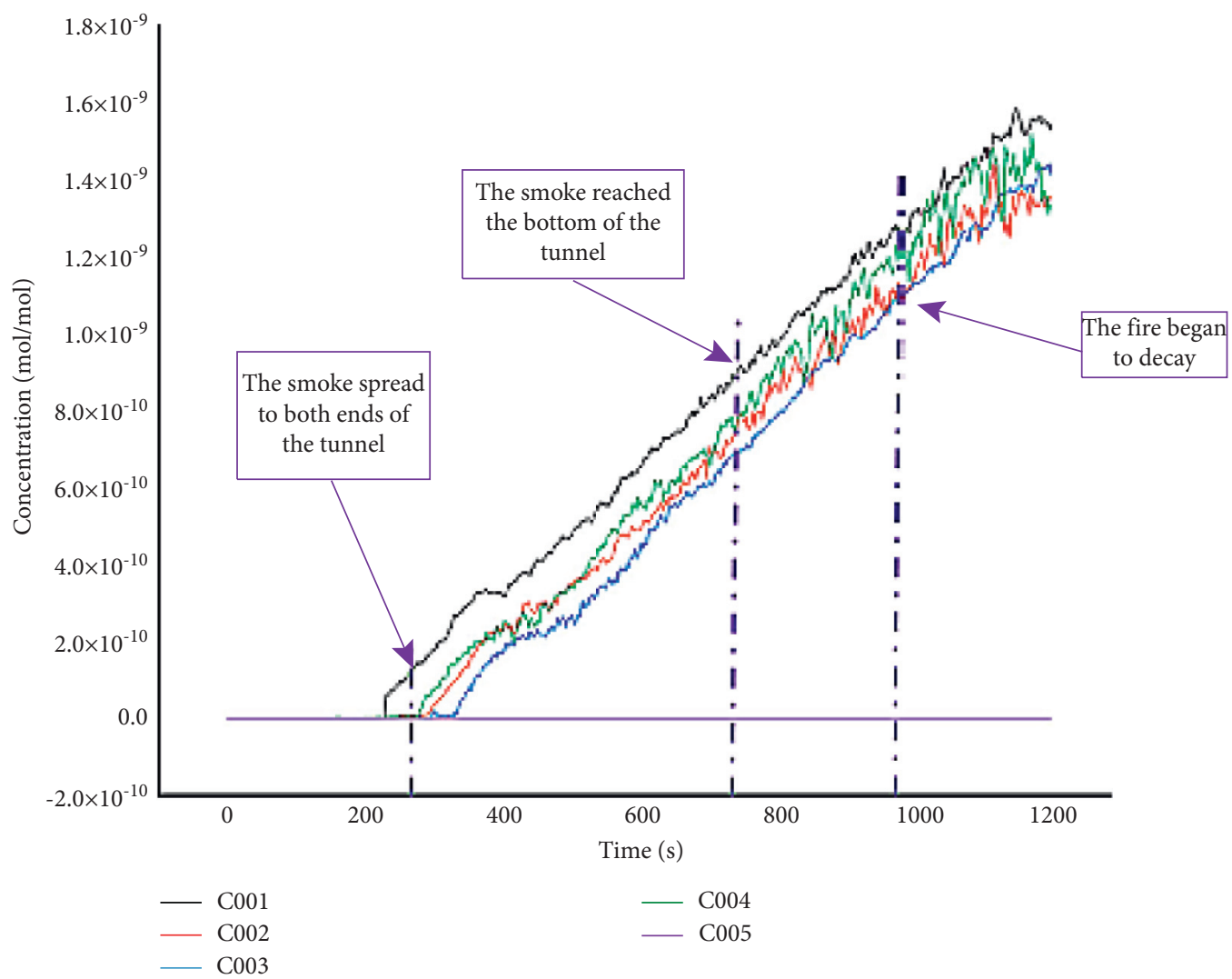

(a)

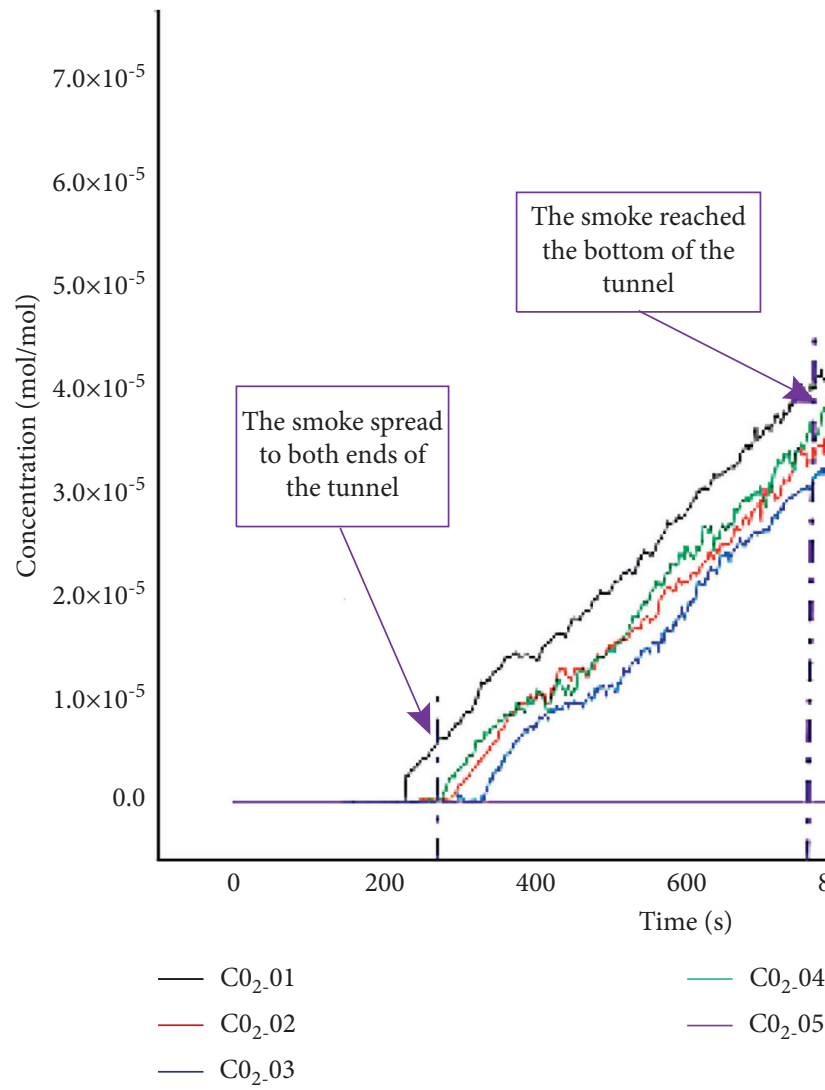

(b)

FIgURE 3: Comparison of smoke concentration changes under working conditions 6. (a) Carbon monoxide concentration. (b) Carbon dioxide concentration. 
faster pace, but their maximum concentration values remained unchanged. The distribution of carbon monoxide and carbon dioxide in the utility tunnel was relatively uniform for the open fire door. When the fire door opening angle decreased, the concentrations of gases at various positions in the tunnel became closer.

A comparison of the simulation results under working conditions 1 and 6 made clear that, when smoke exhaust facilities were added, the increase rates and maximum concentrations of carbon monoxide and carbon dioxide gases in the tunnel declined significantly (Figures 2 and 3).

\section{Conclusions}

Through simulating utility tunnel under different working conditions, this paper obtains the results of smoke spread in the utility tunnel under various conditions. As can be observed from analysis, when measures such as building ceiling screen, changing fire compartmentation tightness, and adding smoke exhaust facilities were taken into account, smoke spread followed the following rules:

(1) When ceiling screens were erected in the utility tunnel, they apparently obstructed smoke spread in the early stage of fire development. Under the premise of guaranteeing minimum visibility in the utility tunnel, a larger ceiling screen height could more significantly obstruct smoke spread. However, when the smoke layer thickness in the smoke cabin exceeded the lower edge of a ceiling screen, the obstructing effect of the ceiling screen on the smoke spread was weakened. When the entire utility tunnel was completely filled with smoke, the ceiling screen barely had any obstructing effect on the smoke spread.

Considering the role of ceiling screens in satisfactorily controlling smoke spread in the early stage of fire development, ceiling screens should be erected in utility tunnel, so that people can be evacuated to a safe region in the early stage of fire development.

(2) When the fire door of the utility tunnel is open, fire smoke entered the adjacent fire compartment through the door. In the early stage of fire development, the smoke spread rate in the adjacent fire compartment was directly proportional to the fire door opening angle; the smoke spread rate in the utility tunnel segment affected by the fire accident was inversely proportional to the fire door opening angle. In the late stage, two utility tunnel segments were completely filled up by fire smoke, and the smoke concentration, in this case, was almost the same as that under the initial working condition. Thus, in the utility tunnel, the fire door between adjacent fire compartments should normally be kept closed to prevent fire smoke from entering adjacent fire compartments through open fire doors.

(3) When smoke exhaust systems were added to the utility tunnel, smoke exhaust fans extracted hot smoke from the utility tunnel. In the early stage of fire development, the smoke layer thickness, concentration, temperature, and spread rate in the utility tunnel all declined. To be specific, smoke spread rate, smoke layer thickness, and smoke layer temperature declined by as much as about $50 \%, 25 \%$, and $32{ }^{\circ} \mathrm{C}$, respectively. In the late stage of fire development, when the entire tunnel was already completely filled up by smoke and hot smoke had already been extracted from the utility tunnel, the smoke layer concentration in the tunnel declined. In contrast, visibility increased by as much as $66 \%$. Therefore, adding smoke exhaust fans in utility tunnel helps to effectively control smoke spread. By contrast, smoke exhaust systems are most effective when it comes to the control of smoke in utility tunnel, and they can satisfactorily lower smoke concentration, improve visibility, and increase people's chance of escape during a fire.

\section{Data Availability}

All data used to support the findings of this study are included within the article.

\section{Conflicts of Interest}

The authors declare that they have no conflicts of interest.

\section{Acknowledgments}

This research was supported by the National Natural Science Foundation of China; Jiangsu Key Laboratory of Fire Safety in Urban Underground Space, China University of Mining and Technology (grant no. 51708546); Research on Liquid Nitrogen Fire Extinguishing Technology for Substation Cable Trench Fire and Emergency Platform System Development Project; and Scientific and Technological Project by State Grid Hebei Electric Power Co., Ltd. (kj2020-041)

\section{References}

[1] L. Sun and C. B. liu, "Fire control analysis on the multi-utility tunnel construction," Chinese Journal of Underground Space and Engineering, vol. 5, no. 3, pp. 616-620, 2009.

[2] Y. S. Lan, Research on Optimal Selection of Automatic FireExtinguishing System for Utility Tunnel, pp. 1-22, South China University of Technology, Guangzhou, 2019.

[3] X. You, H. E. Guangyao, Q. Wang et al., "Current status and development trend of urban underground space in China," Tunnel Construction, vol. 39, no. 2, pp. 173-188, 2019.

[4] D. Guo, G. Zhang, G. Zhu, B. Jia, and P. Zhang, "Applicability of liquid nitrogen fire extinguishing in urban underground utility tunnel," Case Studies in Thermal Engineering, vol. 21, Article ID 100657, 2020.

[5] D. G. Lanin, D. V. Polyakov, and S. G. Tsarichenko, "Justification for the choice of fire extinguishing means for electric cables," Fire and Explosion Safety, vol. 22, no. 2, 2013.

[6] L. Xi, H. M. Zhang, and Z. Y. Long, "Fire extinguishing test of high-pressure water mist in power cable cabin of utility 
tunnel," China Water \& Wastewater, vol. 35, no. 1, pp. 63-67, 2019.

[7] P. Sturm, J. Rodler, T. Thaller, D. Fruhwirt, and P. Fößleitner, "Hot smoke tests for smoke propagation investigations in long rail tunnels," Fire Safety Journal, vol. 105, pp. 196-203, 2019.

[8] F. Chaabat, P. Salizzoni, M. Creyssels et al., "Smoke control in tunnel with a transverse ventilation system: an experimental study," Building and Environment, vol. 167, Article ID 106480, 2020.

[9] L. Q. Chen, Simulation Study of the Fire Smoke Value on a Underground Pipe Gallery, pp. 1-7, Anhui Jianzhu University, Hefei, China, 2018.

[10] Y. H. Wang, "Study on risk factors of operation and maintenance fire in urban underground integrated pipe gallery," Value Engineering, vol. 38, no. 5, pp. 57-60, 2019.

[11] K. Liang, X. Hao, W. An, Y. Tang, and Y. Cong, "Study on cable fire spread and smoke temperature distribution in T-shaped utility tunnel," Case Studies in Thermal Engineering, vol. 14, Article ID 100433, 2019.

[12] H. N. Liu, G. Zhu, and X. Zhou, "Research on the law of smoke movement in utility tunnel under the influence of wind speed," Fire Science and Technology, vol. 37, no. 7, pp. 896-898, 2018.

[13] R. Pan, G. Zhu, Z. Liang, G. Zhang, H. Liu, and X. Zhou, "Experimental study on the fire shape and maximum temperature beneath ceiling centerline in utility tunnel under the effect of curved sidewall," Tunnelling and Underground Space Technology, vol. 99, Article ID 103304, 2020.

[14] M. Altay and S. Ali, "Effect of the relative positions of vehicular blockage on the smoke flow behaviour in a scaled tunnel," Fuel, vol. 255, pp. 115694.1-115694.8, 2019.

[15] Y. Wang and N. Li, "Ventilation system design of comprehensive pipe gallery in Chengbei Road," Suzhou City, GAS \& HEAT, vol. 36, no. 11, pp. 13-17, 2016.

[16] A. H. Zhang, "Fire design of city integrated pipe gallery project," Fire Science and Technology, vol. 36, no. 1, pp. 51-53, 2017.

[17] G. Zhang, H. Li, G. Zhu, and J. Li, “Temperature fields for fire resistance analysis of structures exposed to natural fires in large space buildings," The Structural Design of Tall and Special Buildings, vol. 29, no. 4, 2020.

[18] K. Xiang and L. Li, "Study on fire prevention of the utility tunnel," Safety Now, vol. 41, no. 2, pp. 9-16, 2020. 